\title{
The Structure of Iso-anhydro Vitamin A
}

\author{
Kiyoshi Tsukida, Masayoshi Ito \\ AND FUMIKO IKEDA ${ }^{1}$ \\ Kobe Women's College of Pharmacy, Higashinada-Ku, Kobe \\ (Post No. 658)
}

(Received December 7, 1970)

Iso-anhydro vitamin A, provisionally called, is one of the major degradation products of vitamin $A(I)$. Because of its positive behavior toward Carr-Price reaction and ultraviolet (UV) spectroscopic properties, this compound can not be ignored on the quantitative evaluation of vitamin A. Iso-anhydro vitamin A was first obtained by prolonged treatment of vitamin $\mathrm{A}$ or anhydro vitamin $\mathrm{A}$ (II) with an ethanolic hydrogen chloride (1) and its conversion to chloro-containing "Substance $\mathrm{X}$ " was later described (2). The alternative chemical structure (III) or (IV) deduced from UV spectral data was proposed tentatively for iso-anhydro vitamin A (3). No further criteria on the chemical structure of this compound have been available. We now report that the title compound prepared from anhydro vitamin A $\left(\mathrm{M}^{+}, \mathrm{m} / \mathrm{e} 268 ; \lambda \underset{\max }{\text { hexane }}, 390,368.5\right.$, and $350.5 \mathrm{~m} \mu$ ) and $1 / 30 \mathrm{~N}-\mathrm{HCl}$ in methanol is shown to be a structure $\left(\mathrm{IV}^{\prime}\right)$.
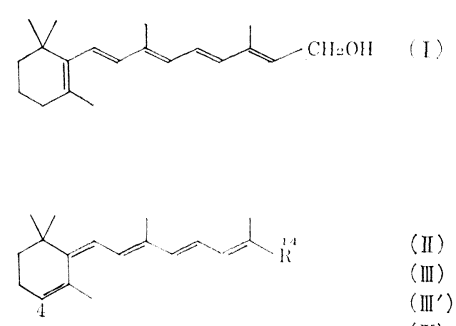

$$
\begin{aligned}
& \text { (II) : } \mathrm{R}=-\mathrm{CH}=\mathrm{CH}_{3} \\
& \text { (III) : } \mathrm{R}=-\mathrm{CH}_{2} \mathrm{CH}_{2} \mathrm{OC}_{2} \mathrm{H}_{5} \\
& \text { (III') : } \mathrm{R}=-\mathrm{CH}_{2} \mathrm{CH}_{2} \mathrm{OCH}_{3} \\
& \text { (IV) : } \mathrm{R}=-\mathrm{CH} \cdot \mathrm{CH}_{3} \\
& \stackrel{1}{\mathrm{OC}_{2} \mathrm{H}_{5}} \\
& \left(\mathrm{I}^{\prime}\right): \mathrm{R}=-\underset{1}{\mathrm{O}} \mathrm{CH}_{3} \cdot \mathrm{CH}_{3}
\end{aligned}
$$

1 月田 潔, 伊藤允好, 池田芙美子.
Iso-anhydro vitamin $\mathrm{A}$, an unstable yellowish viscous oil, can be distilled at $150-5^{\circ}$ (bath temp.) under $0.002 \mathrm{mmHg}$ and its initial blue coloration $\left(\lambda \underset{\max }{\mathrm{CH}_{2} \mathrm{Cl}_{2}} 620 \mathrm{~m} \mu\right.$ ) produced from the compound and $\mathrm{SbCl}_{3}$ in $\mathrm{CH}_{2} \mathrm{Cl}_{2}$ turns into violet $(620$ and $556 \mathrm{~m} \mu)$ or red violet $(555 \mathrm{~m} \mu)$ after standing at room temperature for 2 or 4 minutes, respectively. The compound exhibits UV absorptions in hexane at 365.5, 347, 331.5, and $248 \mathrm{~m} \mu$. Considering a shape of the spectral curve keeping a characteristic fine structure and the positions of $\lambda_{\max }$, this compound is strongly suggested to be a next lower vinylogue of anhydro vitamin A $(3,4)$. The molecular ion peak appears as a base peak at $\mathrm{m} / \mathrm{e} 300$ which is 32 mass units higher than that of the starting material. The presence of a methoxyl group is verified from a nuclear magnetic resonance (NMR) signal at $6.80 \tau$ (3H) along with mass spectrum peaks at $\mathrm{m} / \mathrm{e}$ $269[\mathrm{M}-31(\mathrm{OMe})]$ and $268[\mathrm{M}-32(\mathrm{MeOH})]$. Furthermore, appearance of signals at $6.29 \tau$ (quartet, $1 \mathrm{H}, \mathrm{J}=6.5 \mathrm{cps}$ ) and $8.76 \tau$ (doublet, $3 \mathrm{H}, \mathrm{J}=6.5 \mathrm{cps})$ as well as significant paramagnetic shifts of the three signals $(8.76,6.80$, and $6.29 \tau$ ) caused by tris (dipivalomethanato) europium (5) clearly indicate that this methoxyl group should locate on C-14 and a structure (III') has to be abandoned. Besides UV and NMR spectral information described above, the presence of a signal at ca. $4.3 \tau$ (multiplet, $1 \mathrm{H})$ which can be attributed to a $\mathrm{C}-4$ proton can exclude a 4-methoxy-axerophthene-like 
structure. Our conclusion is further supported by $\nu \underset{\max }{\mathrm{CS}_{2}}$ at 1625 (conj. $\mathrm{C}=\mathrm{C}$ ), 1364 and 1352 (gem. $\mathrm{CH}_{3}$ ), 2830 and $1100(\mathrm{OMe}), 952$ (trans $-\mathrm{CH}=\mathrm{CH}-)$, and $870 \mathrm{~cm}^{-1}(-\mathrm{CH}=\mathrm{C}-)$, and all spectral data are consistent decisively with the structure $\left(\mathrm{IV}^{\prime}\right)$.

\section{REFERENCES}

1. Shantz, E. M., Cawley, J. D., and Embree, N.D.,
J. Am. Chem. Soc., 65, 901 (1943); Isler, O., Huber, W., Ronco, A., and Kofler, M., Helv., 30, 1911 (1947).

2. Guerillot-Vinet, A., Meunier, P., Jouanneteau, J., and Gourevitch, M., Comp. rend., 226, 128 (1948).

3. Oroshnik, W., Science, 119, 660 (1954).

4. Oroshnik, W., Karmas, G., and Mebane, A. D., J. Am. Chem. Soc., 74, 295, 3807 (1952).

5. Eisentraut, K. J., and Sievers, R. E., ibid., 87, 5254 (1965). 